\title{
Academia Nacional de Medicina. Ingreso de nuevos académicos
}

Armando Mansilla-Olivares

Presidente de la Academia Nacional de Medicina de México

Si bien el ambiente en el que se encuentra envuelta la Academia Nacional de Medicina (ANM) es cada vez más sofisticado y complejo por el nivel intelectual, el grado de entrenamiento y la influencia que sus miembros ejercen sobre la evolución de la medicina, este no representa el pilar fundamental en el que se yergue la estructura de la Academia más antigua de toda América, con 155 años de antigüedad, cuyo prestigio sin igual, más que por su longevidad, es el resultado de la magnitud y la trascendencia de la obra de los académicos que nos han precedido, cuyo talento y mente privilegiada y ejemplar han impulsado el desarrollo científico y humanista de la medicina en nuestro país, haciendo de la Academia un templo del que emanan de una manera equilibrada humanismo e innovación científica.

Señoras y señores, miembros de la ANM, distinguidos miembros de la Mesa de Honor, académicos honorarios, señores expresidentes de la ANM, presidentes de Departamentos, invitados especiales y personales, miembros de la mesa directiva:

Nunca antes una agrupación de intelectuales había perdurado tanto ni resistido los embates de la hegemonía del conocimiento, de la evolución y de la modernidad, como lo ha demostrado a través de su historia, de su presente y de la preponderancia de su influencia, la ANM, cuya riqueza, de hecho, estriba en el talento de todos y cada uno de sus miembros, en el trabajo constante e ininterrumpido que desarrollan día con día, así como en la solidez de sus conocimientos y su creatividad que de una manera sólida plasman los académicos mediante su quehacer cotidiano en quienes les rodean, con la sencillez y la soltura que caracterizan el proceder de aquellos que poseen la maestría alcanzada por el dominio del conocimiento y la sabiduría, producto de la constancia y la experiencia adquiridas con un pensamiento abierto, sediento de conocimiento, y una actitud científica indiscutible, dispuesta a luchar invariablemente por la verdad al servicio de la sociedad.

Innumerables han sido los avatares que ha enfrentado a lo largo de la historia la ANM, y a pesar de ello no ha habido un hecho o una circunstancia que haya detenido su devenir, fortaleciendo y engrandeciendo, por el contrario, los pilares sobre los que se yergue su estructura, desbordando la influencia de su conocimiento y quehacer en el desarrollo de la medicina, en la preservación de la salud y en el control y la curación de las enfermedades, a través de su influencia como órgano consultivo del gobierno federal y mediante el trabajo cotidiano de sus miembros, quienes actúan con la certeza de su conocimiento y liderazgo. Es en esta forma como la ANM ha logrado trazar el sendero de la medicina y forjar, con todos y cada uno de los elementos que la componen, los cimientos humanísticos y científicos sobre los que se ha venido esculpiendo, desde hace ya más de 155 años, la medicina contemporánea.

En este extraordinario recinto en el que se respira conocimiento y se percibe sabiduría se llevan a cabo sus sesiones, las que transcurren dentro de una atmósfera de formalidad, de seriedad y de compromiso inquebrantable, resultado de una mezcla que conjuga la sobriedad de su recinto con la participación de los académicos que exponen sus ideas y trabajos desarrollados, sometiéndolos a una discusión abierta, bajo puntos de vista diversos y opiniones sólidamente fundamentadas, que nos remontan a pensar en aquellos que la fundaron e impulsaron a luchar por enriquecer sus propósitos, en un ambiente moderno y progresista,
Gaceta Med Mex. 2018;154(Suppl 2): S5-S6 Disponible en PubMed www.gacetamedicademexico.com 
de libertad y de respeto, que nos conduce a cristalizar pensamientos y acciones genuinas que redundan en el progreso de la ciencia. Es precisamente en este lugar donde un grupo de académicos que, habiendo ingresado en el año 2003, obtiene la titularidad por su constancia y entrega desmedida a la ciencia médica y a la misma ANM en los últimos 15 años; damos la bienvenida a la renovación del talento que nos rodea, con el ingreso de mentes jóvenes de quienes esperamos sean verdaderamente dignos representantes de la ANM y que con ahínco sigan el ejemplo de quienes nos han precedido. Estoy convencido de que los médicos y los científicos a quienes en este día se les otorga la enorme distinción de pasar a formar parte de la ANM como miembros numerarios aquilatan el orgullo extraordinario de lo que esto significa y serán dignos representantes de la actividad médico-científica y humanista que de aquí emana, enarbolando el sentido de pertenencia y la intención seria y genuina de contribuir, en representación de la Academia, con el desarrollo y la evolución científica de la medicina contemporánea en beneficio de nuestra población.
El día de hoy también tengo el privilegio de dar la bienvenida a dos académicos honorarios, uno de ellos médico mexicano sin par, pilar de la dermatología moderna en nuestro país, el Señor Doctor Don Luciano Domínguez Soto; y otro, heredero directo de Branwald e impulsor científico de la cardiología mundial, presidente de la Academia Nacional de Medicina de los EE.UU., el Señor Doctor Victor J. Dzau, quienes vienen a fortalecer, a renovar y a engrandecer los pilares sobre los que se sustenta esta Academia, así como a influenciar de una manera determinante el desarrollo científico en el contexto internacional.

Quiero enfatizar, al igual que hice hace un año desde este mismo estrado y como he hecho a todo lo largo de mi vida académica, que «la ANM no es un coto de poder político o de alguna otra índole, sino un crisol de sabiduría, en el que se funden mentes extraordinariamente brillantes de las más diversas áreas de la medicina, incluyendo la filosofía y lo más recóndito del área molecular y las ciencias exactas».

Dr. Armando Mansilla-Olivares Presidente 